\title{
Development of synthetic simulators for endoscope-assisted repair of metopic and sagittal craniosynostosis
}

\author{
Kyle W. Eastwood, BEng, ${ }^{1,3}$ Vivek P. Bodani, MD, ${ }^{1-3}$ Faizal A. Haji, MD, PhD, ${ }^{4}$ Thomas Looi, MASc, ${ }^{1,3}$ \\ Hani E. Naguib, PhD, ${ }^{3,5,6}$ and James M. Drake, $\mathrm{MBBCh}^{1-3}$ \\ ${ }^{1}$ Center for Image-Guided Innovation and Therapeutic Intervention, The Hospital for Sick Children, Toronto; ${ }^{2}$ Division of \\ Neurosurgery, University of Toronto; ${ }^{3}$ Institute of Biomaterials and Biomedical Engineering, University of Toronto; ${ }^{4}$ Department \\ of Clinical Neurological Sciences, Western University, London, Ontario; ${ }^{5}$ Department of Mechanical and Industrial Engineering, \\ University of Toronto; and ${ }^{6}$ Smart and Adaptive Polymer Laboratory (SAPL), University of Toronto, Ontario, Canada
}

\begin{abstract}
OBJECTIVE Endoscope-assisted repair of craniosynostosis is a safe and efficacious alternative to open techniques. However, this procedure is challenging to learn, and there is significant variation in both its execution and outcomes. Surgical simulators may allow trainees to learn and practice this procedure prior to operating on an actual patient. The purpose of this study was to develop a realistic, relatively inexpensive simulator for endoscope-assisted repair of metopic and sagittal craniosynostosis and to evaluate the models' fidelity and teaching content.
\end{abstract}

METHODS Two separate, 3D-printed, plastic powder-based replica skulls exhibiting metopic (age 1 month) and sagittal (age 2 months) craniosynostosis were developed. These models were made into consumable skull "cartridges" that insert into a reusable base resembling an infant's head. Each cartridge consists of a multilayer scalp (skin, subcutaneous fat, galea, and periosteum); cranial bones with accurate landmarks; and the dura mater. Data related to model construction, use, and cost were collected. Eleven novice surgeons (residents), 9 experienced surgeons (fellows), and 5 expert surgeons (attendings) performed a simulated metopic and sagittal craniosynostosis repair using a neuroendoscope, high-speed drill, rongeurs, lighted retractors, and suction/irrigation. All participants completed a 13-item questionnaire (using 5-point Likert scales) to rate the realism and utility of the models for teaching endoscope-assisted strip suturectomy.

RESULTS The simulators are compact, robust, and relatively inexpensive. They can be rapidly reset for repeated use and contain a minimal amount of consumable material while providing a realistic simulation experience. More than $80 \%$ of participants agreed or strongly agreed that the models' anatomical features, including surface anatomy, subgaleal and subperiosteal tissue planes, anterior fontanelle, and epidural spaces, were realistic and contained appropriate detail. More than $90 \%$ of participants indicated that handling the endoscope and the instruments was realistic, and also that the steps required to perform the procedure were representative of the steps required in real life.

CONCLUSIONS Both the metopic and sagittal craniosynostosis simulators were developed using low-cost methods and were successfully designed to be reusable. The simulators were found to realistically represent the surgical procedure and can be used to develop the technical skills required for performing an endoscope-assisted craniosynostosis repair. https://thejns.org/doi/abs/10.3171/2018.2.PEDS18121

KEYWORDS medical education; simulation; anatomical models; craniosynostosis; neuroendoscopy; technique; craniofacial

$\mathrm{C}$ RANIOSYNOSTOSIS is a developmental defect that occurs in 1:2000 to 1:2500 live births and involves the premature closure of the calvarial sutures. ${ }^{3}$ This condition occurs in many characteristic skull deformations, with closure of the sagittal and metopic sutures among the most common forms. ${ }^{2}$ Untreated, these craniosynostoses may result in persisting visible deformities and ongoing questions about their impact on brain growth and development. ${ }^{7}$

The treatment of craniosynostosis has progressed dramatically over time. With the increasing adoption of endoscopy into neurosurgical practice, there is growing in- 
terest in endoscope-assisted surgical techniques combined with postoperative molding helmet regimens to treat these pathologies. ${ }^{13,14}$ Endoscope-assisted repair of both sagittal and metopic craniosynostosis has been reported as safe and effective, particularly for treating patients younger than 6 months of age. ${ }^{13-15}$ These techniques offer decreased operating times, blood loss, length of stay, and hospital costs, compared to open surgical alternatives. ${ }^{7}$ However, these endoscope-assisted approaches are still relatively new. Some of the technical challenges associated with endoscope-assisted repair compared to open techniques include visualization and hemostasis, which are exacerbated by manipulation difficulties related to using straight endoscopes while working along the curvature of the skull through small incisions. Furthermore, there is a significant degree of variability in the execution of endoscope-assisted strip craniectomies, which in turn has led to variations in outcomes..$^{16}$ There is evidence to suggest as well that unpublished cases with devastating complications from this procedure may exist. There is a need for further research into both patient selection and the development of standardized surgical techniques and training regimens.

Because craniosynostosis is a relatively rare and complex condition, surgical simulators have significant potential to complement direct operative exposure for surgeons learning this procedure. The purpose of this study was to develop a realistic, relatively inexpensive simulator for endoscope-assisted repair of metopic and sagittal craniosynostosis and to evaluate the models' realism and educational value.

\section{Methods}

This research study was conducted in two parts. The first part involved the design and fabrication of two synthetic craniosynostosis models, one simulating sagittal craniosynostosis and the other simulating metopic craniosynostosis. The second part involved an evaluation of the simulators' realism and teaching content. This assessment was based on feedback from neurosurgery residents, fellows, and attending staff who participated in an annual neuroendoscopy training course held at the University of Toronto.

\section{Part I: Design and Fabrication of the Craniosynostosis Simulator}

Simulator Overview

Several technical reports have been published that discuss the surgical approach to endoscope-assisted repair of sagittal and metopic craniosynostosis..$^{13,14,17,19}$ The basic design requirements for the simulators were based on these studies. For the sagittal case, the skull model is placed in the "sphinx" position - prone with head extended - and the key steps involved in the procedure include the following: marking the skin incision location using the anterior fontanelle and lambda as essential bony landmarks, incision of the scalp down to the galea, and scalp elevation at the subgaleal plane of dissection; dissection of the periosteum followed by a burr-hole craniotomy; separation of the dura mater from the skull; and subsequent lateral paramedian osteotomies made with bone-cutting scissors.
For metopic cases, the skull model is positioned as supine with the head in a neutral position, and the key steps involved in the procedure include the following: a skin incision and dissection made anterior to the anterior fontanelle; scalp elevation at the subgaleal plane of dissection along the metopic suture; dissection of the periosteum followed by a burr-hole craniotomy; separation of the dura from the skull; and excision of a bone corridor $5 \mathrm{~mm}$ wide along the metopic suture down to the nasofrontal junction. ${ }^{15}$

\section{Simulator Fabrication}

The development of both models began with selecting $\mathrm{CT}$ and MRI studies of patients presenting with sagittal and metopic craniosynostosis at the Hospital for Sick Children in Toronto, Canada. The imaging data used to develop the sagittal craniosynostosis model are based on a patient at the age of 2 months. The imaging data used to develop the metopic craniosynostosis model are based on a patient at the age of 4 weeks.

Mimics (Materialise NV), an image-processing software, was used to segment the patients' preoperative CT and MR images, producing 3D surface models of the skull and regions of the head (Fig. 1A). These models were further refined using the Magics (Materialise NV) modeling software to eliminate imperfections and to add or generate other support structures. Specifically, Magics was used to split the models into two major components: a reusable model base and a cartridge with a consumable skull insert (Fig. 1B). Because the process for developing both the sagittal and metopic models was similar, the metopic model will be discussed in detail to illustrate the fabrication process.

The reusable metopic model base consists of a rigid plate and a silicone-covered head. The plate and head were designed such that the cartridge can easily be slid into the model as shown (Fig. 1B). The silicone-covered head was constructed by casting Eco-flex liquid silicone (SmoothOn, Inc.) into a "negative" mold. The negative mold was created using Magics by subtracting a 3D surface model of a generic head from a virtual solid rectangular prism. The resulting 3D model, as well as the rigid base plate, was saved in the stereolithography (STL) file format and 3Dprinted using a Projet 4500 printer (3D Systems, Inc.). The models were iteratively developed and ultimately printed in batches of 10, and the printing process required approximately 18-20 hours with minimal labor.

The cartridge used in the metopic model consists of two parts, the cartridge base and a consumable skull insert. The cartridge base was also designed using Magics but was 3D-printed from ABS material using a Lulzbot Taz 6 (Aleph Objects, Inc.). This material was selected for the cartridge base because it is water resistant, which is important for the longevity of the model when simulating repeated CSF leakages using water. The consumable skull insert was printed using a Projet 4500 printer because this material (VisiJet C4 Spectrum plastic material) behaves more like bone when cut and drilled.

Following printing, the consumable skull insert was manually modified to include several additional anatomical features. A dura layer was secured to the inferior sur- 


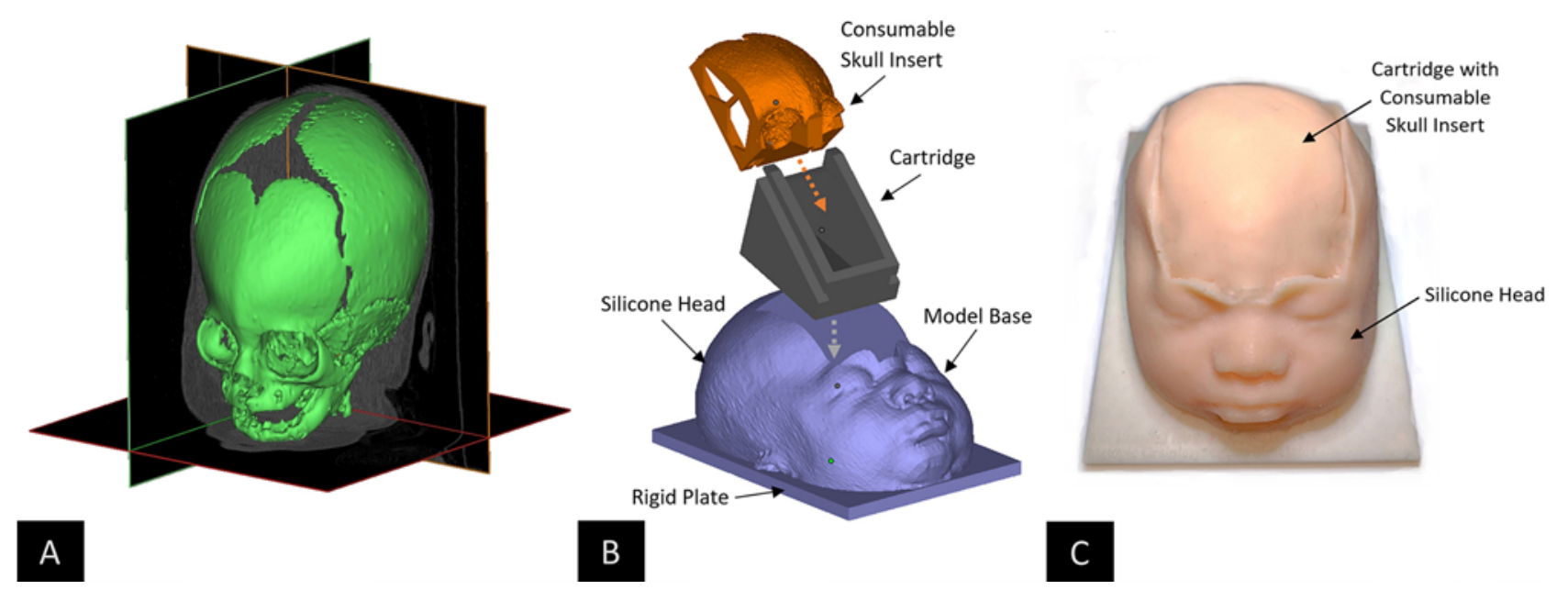

FIG. 1. The 3D surface model of metopic skull segmented from DICOM using Mimics software (A), assembly of reusable model base and cartridge using Magics software (B), and final metopic model assembled (C). Figure is available in color online only.

face of the metopic skull bone and can be seen in Fig. 2A through the fontanelle. The dura was simulated by constructing a silicone-okawara paper laminate sheet that was less than $1 \mathrm{~mm}$ in thickness. A periosteal layer was added to the superficial surface of the skull (Fig. 2B) and was constructed using a variation of the material used for the dura. The skull insert assembles onto the cartridge base, which is used to hold a water balloon that lies inferior to the dura (Fig. 2C). This configuration is used to simulate the dura-covered brain and CSF. Superficial to the periosteal layer, the remaining layers of the scalp were cast from thin films of Eco-flex liquid silicone and Eco-flex gel silicone (Smooth-On, Inc.) (Fig. 2D). The loose connective tissue layer between the galea aponeurotica and periosteum was simulated using Zinsser aerosol shellac film (Rust-Oleum) that creates loose adhesion and allows for a subgaleal dissection.

\section{Part II: Realism and Educational Value of Craniosynostosis Simulators}

\section{Participants and Data Collection}

Study participants were recruited from a neuroendoscopy training course hosted by the Division of Neurosurgery at the University of Toronto. The participants included residents (postgraduate year [PGY] 1-6), fellows, and staff surgeons. Under the supervision of an expert, each participant was asked to independently perform an endoscope-assisted repair of both a sagittal and metopic craniosynostosis. A standard neuroendoscope and instruments were used, including a $0^{\circ}$ rigid endoscope (KARL STORZ GmbH \& Co. KG), Midas Rex electric drill (Medtronic), lighted retractor (Lumitex, Inc.), Leksell rongeur, angled Kerrison punches, and Mayo scissors. Irrigation with normal saline and suction were also provided.

Following the procedure, the study participants com-

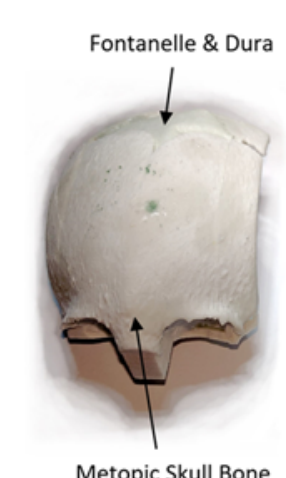

A

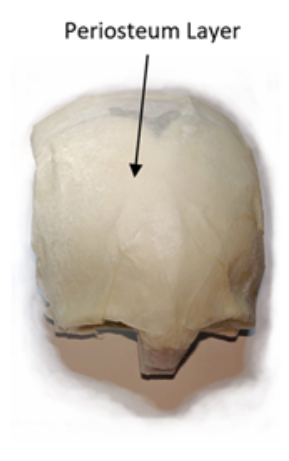

B
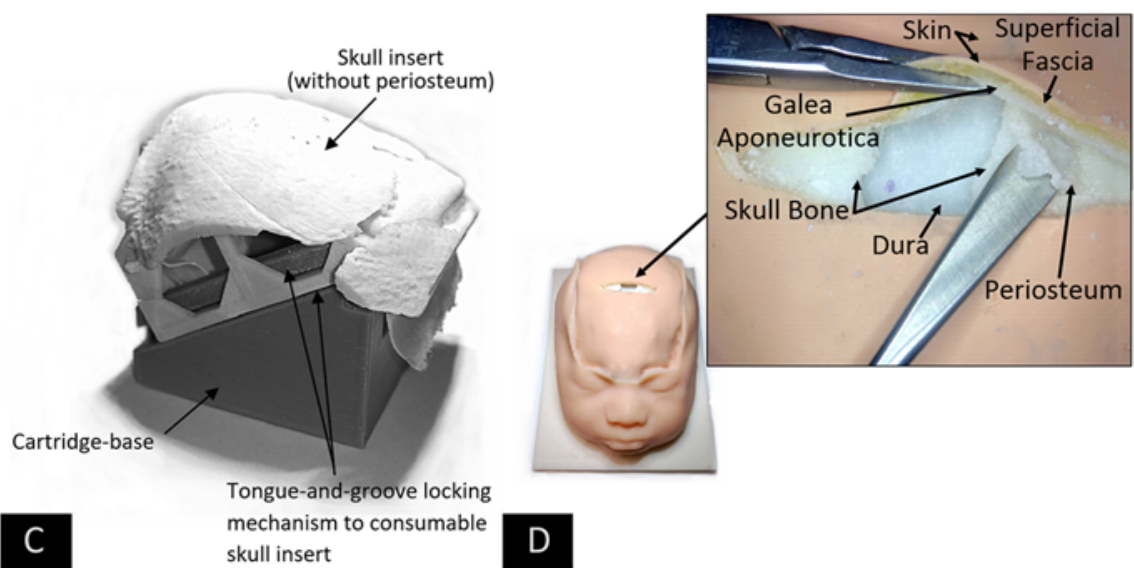

FIG. 2. Skull insert component of cartridge showing dura (A). Skull insert with periosteum secured to the superficial surface (B). Skull insert and cartridge base assembled with water-filled balloon (scalp not shown) (C). Fully assembled metopic model with partial dissection displaying tissue layers (D). Figure is available in color online only. 


\begin{tabular}{|c|c|c|c|c|c|c|}
\hline \multirow[b]{2}{*}{ Item No. } & \multirow[b]{2}{*}{ Questionnaire Item } & \multicolumn{5}{|c|}{ Likert Score } \\
\hline & & $\begin{array}{l}\text { Strongly } \\
\text { Disagree-1 }\end{array}$ & Disagree-2 & Neutral-3 & Agree-4 & $\begin{array}{l}\text { Strongly } \\
\text { Agree-5 }\end{array}$ \\
\hline \multirow[t]{3}{*}{ Anatomy } & $\begin{array}{l}\text { 1. Surface anatomy was realistic and appropriately detailed for } \\
\text { planning and performing the skin incisions. }\end{array}$ & $0(0 \%)$ & $0(0 \%)$ & $2(11 \%)$ & $9(47 \%)$ & $8(42 \%)$ \\
\hline & $\begin{array}{l}\text { 2. Scalp and subperiosteal tissue plane were realistic and had } \\
\text { appropriate detail for exposure of the anterior fontanelle } \\
\text { and metopic suture. }\end{array}$ & $0(0 \%)$ & $1(5 \%)$ & $2(11 \%)$ & $12(63 \%)$ & $4(21 \%)$ \\
\hline & $\begin{array}{l}\text { 3. The skull and anterior fontanelle, fused metopic suture, and } \\
\text { epidural space were realistic and had appropriate detail } \\
\text { required to perform the surgery. }\end{array}$ & $0(0 \%)$ & $1(5 \%)$ & $2(11 \%)$ & $6(32 \%)$ & $10(53 \%)$ \\
\hline \multirow{4}{*}{$\begin{array}{l}\text { Instrument } \\
\text { handling }\end{array}$} & 4. Endoscope handling was realistic. & $0(0 \%)$ & $0(0 \%)$ & $0(0 \%)$ & $6(32 \%)$ & $13(68 \%)$ \\
\hline & 5. Instrument handling was realistic. & $0(0 \%)$ & $1(5 \%)$ & $1(5 \%)$ & $5(26 \%)$ & $12(63 \%)$ \\
\hline & 6. The haptic (tactile) feedback from the simulator was realistic. & $0(0 \%)$ & $0(0 \%)$ & $2(11 \%)$ & $7(37 \%)$ & $10(53 \%)$ \\
\hline & $\begin{array}{l}\text { 7. The response of the tissue to manipulation by the endoscope } \\
\text { and instruments was realistic. }\end{array}$ & $0(0 \%)$ & $0(0 \%)$ & $3(16 \%)$ & $10(53 \%)$ & $6(32 \%)$ \\
\hline \multirow[t]{3}{*}{$\begin{array}{l}\text { Content of } \\
\text { procedure }\end{array}$} & $\begin{array}{l}\text { 8. Steps required to complete the task were representative of } \\
\text { the steps for the real procedure. }\end{array}$ & $0(0 \%)$ & $0(0 \%)$ & $3(16 \%)$ & $9(47 \%)$ & $7(37 \%)$ \\
\hline & $\begin{array}{l}\text { 9. Skills required to complete the task were representative of } \\
\text { the skills required for the real procedure. }\end{array}$ & $0(0 \%)$ & $0(0 \%)$ & $4(21 \%)$ & $7(37 \%)$ & $8(42 \%)$ \\
\hline & 10. This task was technically challenging. & $1(5 \%)$ & $0(0 \%)$ & $5(26 \%)$ & $10(53 \%)$ & $3(16 \%)$ \\
\hline \multirow[t]{3}{*}{ Task fidelity } & 11. The simulator suspended disbelief.* & $0(0 \%)$ & $0(0 \%)$ & $3(18 \%)$ & $8(47 \%)$ & $6(35 \%)$ \\
\hline & 12. The simulator environment is realistic of the real-life situation. & $0(0 \%)$ & $1(5 \%)$ & $2(11 \%)$ & $12(63 \%)$ & $4(21 \%)$ \\
\hline & $\begin{array}{l}\text { 13. Real-life factors, situations, and variables were built into the } \\
\text { simulation scenario.* }\end{array}$ & $0(0 \%)$ & $1(6 \%)$ & $4(24 \%)$ & $10(59 \%)$ & $2(12 \%)$ \\
\hline
\end{tabular}

* For items 11 and $13, n=17$.

pleted a questionnaire regarding the teaching effectiveness and realism of the simulator. The questionnaire included 13 items (Tables 1 and 2), with items 1-3 focused on the simulator's representation of surgical anatomy, items 4-7 focused on instrument handling, items $8-10$ considered the models' representation of the content of the procedure, and items 11-13 on the realism of the model. Using a 5-point Likert scale, the surgeons were asked to rate their level of agreement with each item ranging from 1 (strongly disagree) to 5 (strongly agree). The participants were also encouraged to provide free-text comments regarding the simulators' effectiveness and realism for training and educational purposes.

\section{Data Analysis}

The questionnaire data were analyzed using the $\mathrm{R}$ version 3.2.0 (The R Foundation) statistical package. The distribution of the responses (Tables 1 and 2) for each item was calculated, and any items that were partially or incorrectly completed were excluded from the analysis. The mean and median ratings of the simulator's representation of surgical anatomy (items 1-3), the rating of instrument handling (items 4-7), rating of the content of the procedure (items 8-10), and the realism of the models (items 11-13) were calculated. Scores from each questionnaire item were subsequently analyzed using both a KruskallWallis test and 1-way ANOVA, to identify any statistically significant differences in ratings between the evaluator groups: novices (PGY 1-6), experienced trainees (fellows), and experts (staff neurosurgeons).

The qualitative feedback obtained from the surveys was organized by the same themes, namely surgical anatomy, instrument handling, procedure content, and model realism. The responses were coded and recurring items were grouped. Coded items that occurred more than three times are described in the results below.

\section{Results}

\section{Part I: Construction Logistics and Cost}

Two craniosynostosis simulators, metopic and sagittal variations, were successfully built at low cost and with minimal consumable components. These simulators were pilot tested during a neuroendoscopic training course, and were found by surgeons to realistically mimic the mechanical properties and the various stages of these procedures (Figs. 3 and 4).

For the sagittal simulator, the model was designed to mimic the sphinx patient position that is routinely used in surgery. Additionally, realistic landmarks, including the anterior fontanelle and the lambda, were included on the skull and can be palpated through the skin. The scalp, which is approximately $2.5 \mathrm{~mm}$ thick, was designed to include multiple layers, such as the skin, subcutaneous fat, galea, and periosteum. A subgaleal dissection plane was built into the model by loosely adhering the galea to the 
TABLE 2. Summary of questionnaire results for sagittal model $(n=23)$

\begin{tabular}{|c|c|c|c|c|c|c|}
\hline \multirow[b]{2}{*}{ Item No. } & \multirow[b]{2}{*}{ Questionnaire Item } & \multicolumn{5}{|c|}{ Likert Score } \\
\hline & & $\begin{array}{c}\text { Strongly } \\
\text { Disagree-1 }\end{array}$ & Disagree-2 & Neutral-3 & Agree-4 & $\begin{array}{l}\text { Strongly } \\
\text { Agree-5 }\end{array}$ \\
\hline \multirow[t]{3}{*}{ Anatomy } & $\begin{array}{l}\text { 1. Surface anatomy was realistic and appropriately detailed for } \\
\text { planning and performing the skin incisions. }\end{array}$ & $0(0 \%)$ & $1(4 \%)$ & $2(9 \%)$ & $13(57 \%)$ & $7(30 \%)$ \\
\hline & $\begin{array}{l}\text { 2. Scalp and subperiosteal tissue plane were realistic and had } \\
\text { the appropriate detail required for exposure of the anterior } \\
\text { fontanelle and sagittal suture. }\end{array}$ & $0(0 \%)$ & $2(9 \%)$ & $3(13 \%)$ & $14(61 \%)$ & $4(17 \%)$ \\
\hline & $\begin{array}{l}\text { 3. The skull and anterior fontanelle, fused sagittal suture, and } \\
\text { epidural space were realistic and had appropriate detail } \\
\text { required to perform the surgery. }\end{array}$ & $0(0 \%)$ & $2(9 \%)$ & $2(9 \%)$ & $12(52 \%)$ & $7(30 \%)$ \\
\hline \multirow{4}{*}{$\begin{array}{l}\text { Instrument } \\
\text { handling }\end{array}$} & 4. Endoscope handling was realistic. & $0(0 \%)$ & $0(0 \%)$ & $0(0 \%)$ & $8(35 \%)$ & $15(65 \%)$ \\
\hline & 5. Instrument handling was realistic. & $0(0 \%)$ & $0(0 \%)$ & $1(4 \%)$ & $10(43 \%)$ & $12(52 \%)$ \\
\hline & 6. The haptic (tactile) feedback from the simulator was realistic. & $0(0 \%)$ & $0(0 \%)$ & $5(22 \%)$ & $6(26 \%)$ & $12(52 \%)$ \\
\hline & $\begin{array}{l}\text { 7. The response of the tissue to manipulation by the endoscope } \\
\text { and instruments was realistic. }\end{array}$ & $0(0 \%)$ & $0(0 \%)$ & $3(13 \%)$ & $12(52 \%)$ & $8(35 \%)$ \\
\hline \multirow[t]{3}{*}{$\begin{array}{l}\text { Content of } \\
\text { procedure }\end{array}$} & $\begin{array}{l}\text { 8. Steps required to complete the task were representative of } \\
\text { the steps required to complete the real procedure. }\end{array}$ & $0(0 \%)$ & $0(0 \%)$ & $0(0 \%)$ & $13(57 \%)$ & $10(43 \%)$ \\
\hline & $\begin{array}{l}\text { 9. The skills required to complete the task were representative } \\
\text { of the skills required to complete the real procedure. }\end{array}$ & $0(0 \%)$ & $0(0 \%)$ & $4(17 \%)$ & $9(39 \%)$ & $10(43 \%)$ \\
\hline & 10. This task was technically challenging.* & $2(9 \%)$ & $0(0 \%)$ & $8(36 \%)$ & $6(27 \%)$ & $6(27 \%)$ \\
\hline \multirow[t]{3}{*}{ Task fidelity } & 11. The simulator suspended disbelief. ${ }^{*}$ & $0(0 \%)$ & $0(0 \%)$ & $6(27 \%)$ & $12(55 \%)$ & $4(18 \%)$ \\
\hline & 12. The simulator environment is realistic of the real-life situation. & $0(0 \%)$ & $1(4 \%)$ & $4(17 \%)$ & $12(52 \%)$ & $6(26 \%)$ \\
\hline & $\begin{array}{l}\text { 13. Real-life factors, situations, and variables were built into the } \\
\text { simulation scenario. }\end{array}$ & $0(0 \%)$ & $3(13 \%)$ & $6(26 \%)$ & $11(48 \%)$ & $3(13 \%)$ \\
\hline
\end{tabular}

* For items 10 and $11, n=22$.

periosteum, and can be easily established by blunt dissection. Similarly, the periosteal layer is designed such that it can be resected from the skull surface, but with significantly more adherence than the subgaleal dissection. The dural layer was constructed from a thick, fibrous, watertight material, and can be punctured to simulate a dural tear and CSF leak. The features included in the metopic model are identical, with a few additions. For example, the model is oriented such that the patient is positioned supine. Also, the nasofrontal junction can be visualized using the endoscope, and is used as the reference landmark for the metopic osteotomy.

Both of these models are compatible with standard neuroendoscopes and equipment, and can be set up within minutes. For repeated use and training, the consumable cartridges can be rapidly replaced to reset the scenario. The models do not require maintenance or specialized storage conditions, and can be easily cleaned. To produce the reusable metopic model base requires 8 hours, with 2-3 hours of labor, at a cost in Canadian dollars (CAD) of $\$ 70.00$ for materials. A batch of 10 metopic consumable cartridges requires 24 hours to build, with 4 hours of labor and $\$ 25.00 \mathrm{CAD}$ of material per cartridge. To produce the reusable sagittal model base costs approximately $\$ 200.00$ CAD. A batch of 10 sagittal consumable cartridges similarly requires 24 hours to build, with 4 hours of labor and $\$ 50.00$ CAD of material per cartridge. These models are available in limited quantities for academic courses and can be fabricated on a cost-recovery basis. These data do not consider the costs associated with the computer, modeling software, and 3D printer used to produce the simulators.

\section{Part II: Evaluation of Realism and Teaching Effectiveness}

Twenty-five participants were recruited for the validation study: 11 novices (PGY 1 [ $\mathrm{n}=2$ ], PGY 2 [n =3], PGY $3[\mathrm{n}=3]$, PGY $4[\mathrm{n}=1]$, PGY $6[\mathrm{n}=2]) ; 9$ experienced trainees (fellows); and 5 experts (interquartile range 12-26 years in practice). The median number of metopic or sagittal craniosynostoses performed by the entire group either as the primary or assistant surgeon was 14 (interquartile range 2-49). One of the investigators is included in the survey group, and to reduce bias, this individual was not involved in the data analysis.

The results from the questionnaire for the metopic model are reported in Table 1. Six participants were omitted from the metopic analysis and 2 from the sagittal analysis because they did not complete a majority of the items on the questionnaire. The results from the questionnaire for the sagittal model are reported in Table 2. Two participants were omitted from items 11 and 13 because these items were incomplete. For both models, more than $80 \%$ of respondents either agreed or strongly agreed that the surface anatomy was realistic and appropriately detailed for planning and performing the skin incisions, and that the response of tissue to manipulation by the endoscope 


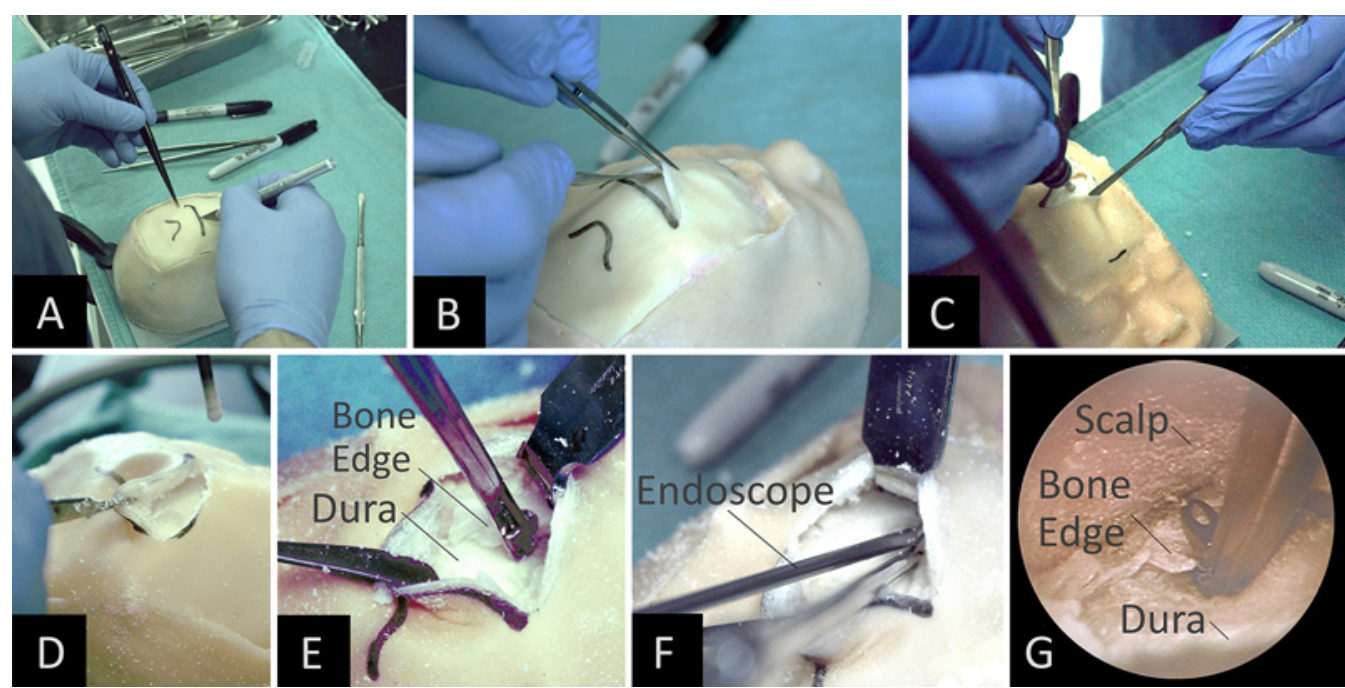

FIG. 3. Photographs of metopic craniosynostosis simulator showing stages of procedure: planning and initial incision (A); subgaleal dissection and dissection of periosteum (B); placement of burr hole (C and D); expansion of burr hole with punches/rongeurs (E); placement of endoscope (F); and endoscopic view showing dissection of dura from inferior skull surface and excision of bone (G). Figure is available in color online only.

and the instruments was realistic. Additionally, more than $90 \%$ of respondents found that the handling of the endoscope and instruments within the models was realistic. Most participants agreed or strongly agreed that the skull, anterior fontanelle, fused metopic and sagittal sutures, and epidural space were realistic and had appropriate detail. Most participants indicated as well that both the skills and steps required to complete the procedures were representative of those required to complete the actual procedure. The lowest-scoring sections all belong to the "Content of Procedure" section, where $79 \%$ of respondents agreed or strongly agreed that the steps required to complete the procedure were representative of the real experience. The free-text responses associated with these items indicate that the majority of respondents desire the simulation to include bone hemostasis. Overall, $100 \%$ of respondents indicated that they would use this simulator for their personal training or the training of their residents and fellows in the future.

The overall ratings of the anatomy, instrument handling, content of procedure, and task fidelity are summarized in Table 3. No statistically significant differences were found between the novice, experienced, and expert groups' ratings using both the Kruskal-Wallis test and a 1-way ANOVA analysis.

Analysis of the qualitative data revealed many positive comments, including general summaries such as "great simulator-instruments same as intraoperative handlingimitates ideal situation," "excellent realism, especially pericranium," and "really good, great for teaching." In terms of constructive criticism, the three most common comments were the need to include bleeding, the skin being "too stretchy," and the dura not being adherent enough to the bone.

\section{Discussion}

Clinical reports of endoscope-assisted repair of metopic and sagittal craniosynostosis have shown these procedures to be safe and effective. ${ }^{13-15}$ However, this technique is not yet widely used, in part because of the learning curve involved in working with the endoscope. Furthermore, to learn, practice, and perfect this technique requires exposure to a large number of cases, which is not always possible. These limitations are common to many neurosurgical procedures, and as a result there has been growing interest in using simulators to train surgeons in risk-free environments without constraints on resources or time. ${ }^{1,4,10,18} \mathrm{Sev}$ eral studies have demonstrated the benefits of simulators, which include accelerated learning curves and improvements in real-life surgical technique, which directly improve patient outcomes. ${ }^{9,20,21}$

To the best of our knowledge, there are not presently any simulators that have been specifically developed for training in metopic endoscope-assisted craniosynostosis. However, the ASPEN simulator (Pro Delphus) is designed for training surgeons in open biparietal remodeling, which is used in scaphocephaly correction. ${ }^{8}$ In addition to this simulator, a polyurethane foam-filled, 3D-printed skull replica has been reported.12 Alternatively, animal models have been used, which include fresh cadaveric sheep cranium for training residents in anterior plagiocephaly, trigonocephaly, and brachycephaly remodeling. ${ }^{11}$

Cadaveric animal models are advantageous because they exhibit realistic tissue properties and generally have a low cost. However, the training utility of such approaches is limited because of the significant differences that exist in calvarial shape between the animal and the presentation of clinical craniosynostosis in humans. Also, the bone thickness in animals is significantly greater, which may detract from the simulation experience. Instead, synthetic models can be designed to better mimic the gross anatomy that presents in craniosynostosis. However, the currently available synthetic models either achieve high realism with the tradeoff of significant consumable material and 


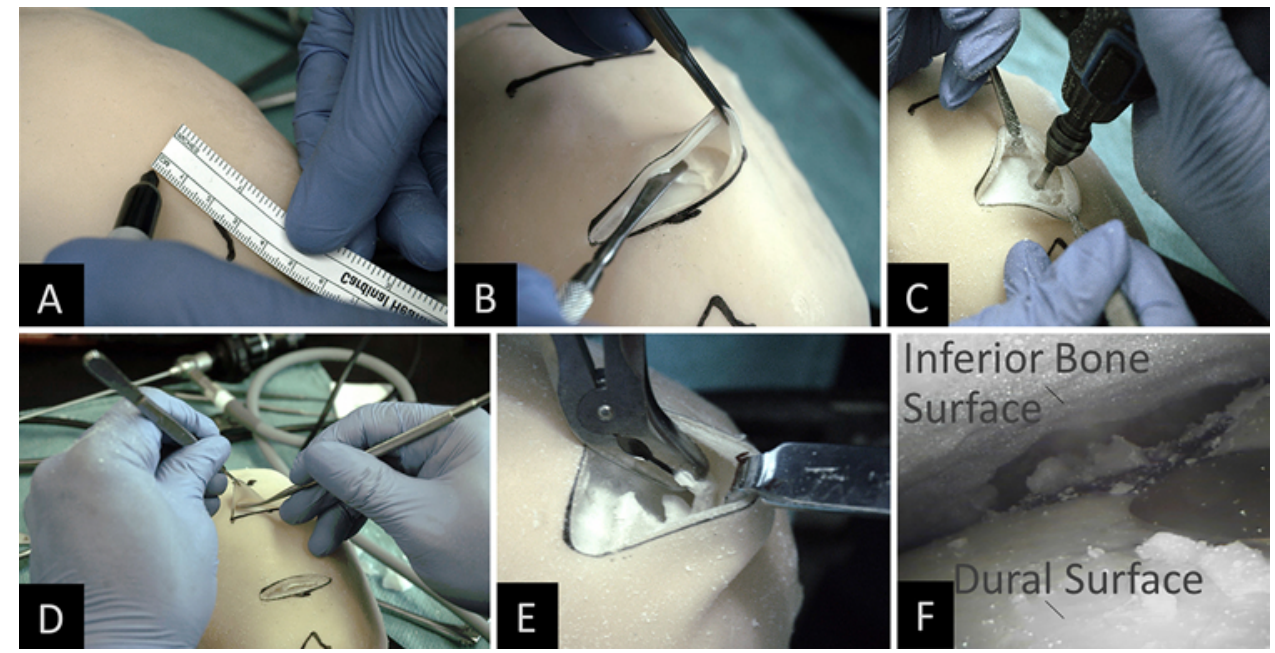

FIG. 4. Photographs of sagittal craniosynostosis simulator showing various stages of the procedure, including planning the incision (A); initial anterior incision, subgaleal dissection, and dissection of periosteum (B); placement of anterior burr hole (C); posterior incision and subgaleal dissection (D); expansion of anterior burr hole (E); and endoscopic view depicting dissection of dura from inferior surface of skull $(\mathbf{F})$. Figure is available in color online only.

higher costs, or arguably lower realism with reduced cost. We have aimed to develop synthetic training models that achieve a better balance between cost and realism.

The primary advantage of the models presented in this work is their use of cartridge mechanisms, which offers significant cost reduction in model fabrication and the opportunity for customizing the cartridge to include procedure specificity. Because the simulators are intended to replicate an endoscope-assisted procedure, the workspace for the surgery is small compared to open procedures, and can be easily contained within a compact cartridge. With the cartridge-based approach, the simulators can be rapidly reset and the amount of consumable material is minimized. These benefits allow for an excellent balance between fidelity, detail, and cost. Furthermore, these models are extremely portable and do not require any special maintenance or storage. This approach to the model design can also be easily extended to other patient skull model configurations, where the model base, the scalp, and much of the cartridge can be reused. These benefits may enable the production of more patient-specific training models. More than $80 \%$ of respondents either agreed or strongly agreed that the surface anatomy was realistic and appropriately detailed and that the handling of the endoscope and instruments within the models was realistic. Furthermore, $100 \%$ of the respondents indicated that they would use this simulator for their own personal training or the training of residents or fellows in techniques for endoscopic suturectomy.

During the model development and evaluation process, some limitations of the simulator were identified. First, the models do not include bleeding in any of the scalp dissection planes or in the synthetic bone. Additionally, the materials used to construct the models cannot be cauterized. For the purposes of training, both of these limitations were overcome by instructing the study participants to mimic cauterization of the exposed skull surfaces following drilling or cutting by marking the edges with ink. However, the visualization challenges posed by bleeding are important training elements that should be included in future versions of the simulator. This missing feature was highlighted by the lower item ratings in the "Content of Procedure" results. Here, many respondents noted the absence of bleeding in the open-ended feedback they provided. A sagittal sinus bleeding scenario was incorporated into the models, but this element was not tested during the model evaluations described in these experiments. In fact, the feedback collected from the participants included comments requesting that the models provide a simulation of this complication. Therefore, this bleed scenario will be included in the future. Surgeons also indicated that the model's scalp was too compliant and could be easily stretched. Because the model's scalp was "stretchy," it could be more easily retracted, which unrealistically improved the operator's view and deterred the surgeons from using the endoscope. Future iterations of the model will be constructed using higher-durometer silicone in order to make the scalp more stiff, which will better mimic actual operative conditions. Also, currently the models are not designed to allow for instrument motion tracking or monitoring of tool-tip forces to evaluate surgeon performance.

TABLE 3. Summary of survey Likert ratings by section for metopic and sagittal models

\begin{tabular}{lcccc}
\hline Model & Anatomy & $\begin{array}{c}\text { Instrument } \\
\text { Handling }\end{array}$ & $\begin{array}{c}\text { Content of } \\
\text { Procedure }\end{array}$ & $\begin{array}{c}\text { Task } \\
\text { Fidelity }\end{array}$ \\
\hline Metopic & & & & \\
\hline Mean (SD) & $4.21(0.77)$ & $4.43(0.70)$ & $4.05(0.83)$ & $3.98(0.75)$ \\
Median & 4 & 5 & 4 & 4 \\
\hline Sagittal & \multicolumn{5}{c}{} \\
\hline Mean (SD) & $4.01(0.81)$ & $4.41(0.67)$ & $4.12(0.90)$ & $3.83(0.80)$ \\
Median & 4 & 5 & 4 & 4 \\
\hline
\end{tabular}


Some additional limitations were identified in the design of the evaluation study. First, there is an inherent bias in administering a rating questionnaire directly to participants. This limitation was minimized during the course by anonymizing the responders and using impartial volunteers to collect the surveys. Additionally, some of the participants (PGY 1 to PGY 3) had little experience performing craniosynostosis procedures, which limited their ability to evaluate the realism and teaching value of the models. To address this limitation, the phrasing and the scope of the individual survey questions were designed to capture sub-elements of the procedure that are not specific to craniosynostosis. For example, the questions focusing on anatomy or instrument handling apply to many different surgical scenarios that the participants probably will have had experience with. Recall bias when comparing the simulator to previous actual surgical experiences is also a limitation, as well as the small sample size of participants in the study.

Although this work has assessed the perceived educational value of the metopic and sagittal craniosynostosis simulators, we did not specifically consider whether training on the simulator will improve the technical skills of surgeons in endoscopic suturectomy. To complete such an assessment, specific measures for evaluating the technical skills and an expert consensus on the procedural steps required to safely perform a suturectomy must be developed. The development of such assessment measures is currently underway for many procedures; for example, the NeuroEndoscopic Ventriculostomy Assessment Tool (NEVAT) has been developed to standardize the training for endoscopic third ventriculostomy. ${ }^{5,6}$ In the future, the development of a similar standardized protocol would be beneficial for endoscopic suturectomy. Also, following future refinements to the model's design, the simulators will be assessed during actual resident and fellow rotations, before and after real endoscopic synostosis surgery, to further assess the model as a training aid.

\section{Conclusions}

We have developed reusable, patient- and procedurespecific metopic and sagittal craniosynostosis simulators using low-cost methods. The simulators were found to realistically represent the surgical procedure, and can be used to develop the technical skills required for performing an endoscope-assisted repair of craniosynostosis. Future iterations of the models will focus on including bleeding and the management of more emergency situations-for example, injury to the sagittal sinus. Following updates to the models, future work will focus on developing objective performance metrics, which include expert-rated assessment tools and conducting additional validation studies.

\section{Acknowledgments}

The authors thank all of the trainees and faculty for their participation in the survey and, specifically, Dr. Gerben E. Breimer for his input into model development techniques. Kyle W. Eastwood received the Vanier Canada Graduate Scholarship, Canadian Institutes of Health Research.

\section{References}

1. Aboud E, Al-Mefty O, Yaşargil MG: New laboratory model for neurosurgical training that simulates live surgery. J Neurosurg 97:1367-1372, 2002

2. Bennett KG, Bickham RS, Robinson AB, Buchman SR, Vercler CJ: Metopic craniosynostosis: a demographic analysis outside an urban environment. J Craniofac Surg 27:544547,2016

3. Boulet SL, Rasmussen SA, Honein MA: A population-based study of craniosynostosis in metropolitan Atlanta, 19892003. Am J Med Genet A 146A:984-991, 2008

4. Breimer GE, Bodani V, Looi T, Drake JM: Design and evaluation of a new synthetic brain simulator for endoscopic third ventriculostomy. J Neurosurg Pediatr 15:82-88, 2015

5. Breimer GE, Haji FA, Cinalli G, Hoving EW, Drake JM: Validity evidence for the Neuro-Endoscopic Ventriculostomy Assessment Tool (NEVAT). Oper Neurosurg (Hagerstown) 13:60-68, 2017

6. Breimer GE, Haji FA, Hoving EW, Drake JM: Development and content validation of performance assessments for endoscopic third ventriculostomy. Childs Nerv Syst 31:12471259,2015

7. Chan JW, Stewart CL, Stalder MW, St Hilaire H, McBride L, Moses MH: Endoscope-assisted versus open repair of craniosynostosis: a comparison of perioperative cost and risk. J Craniofac Surg 24:170-174, 2013

8. Coelho G, Warf B, Lyra M, Zanon N: Anatomical pediatric model for craniosynostosis surgical training. Childs Nerv Syst 30:2009-2014, 2014

9. Haase J, Boisen E: Neurosurgical training: more hours needed or a new learning culture? Surg Neurol 72:89-97, 2009

10. Haji FA, Dubrowski A, Drake J, de Ribaupierre S: Needs assessment for simulation training in neuroendoscopy: a Canadian national survey. J Neurosurg 118:250-257, 2013

11. Hicdonmez T, Parsak T, Cobanoglu S: Simulation of surgery for craniosynostosis: a training model in a fresh cadaveric sheep cranium. Technical note. J Neurosurg 105 (2 Suppl):150-152, 2006

12. Jeong YJ, Lee JY: Polyurethane foam-filled skull replica of craniosynostosis for surgical training. J Craniofac Surg 27:e291-e292, 2016

13. Jimenez DF, Barone CM: Endoscopic technique for sagittal synostosis. Childs Nerv Syst 28:1333-1339, 2012

14. Jimenez DF, Barone CM, Cartwright CC, Baker L: Early management of craniosynostosis using endoscopic-assisted strip craniectomies and cranial orthotic molding therapy. Pediatrics 110:97-104, 2002

15. Keshavarzi S, Hayden MG, Ben-Haim S, Meltzer HS, Cohen SR, Levy ML: Variations of endoscopic and open repair of metopic craniosynostosis. J Craniofac Surg 20:1439-1444, 2009

16. Kung TA, Vercler CJ, Muraszko KM, Buchman SR: Endoscopic strip craniectomy for craniosynostosis: do we really understand the indications, outcomes, and risks? J Craniofac Surg 27:293-298, 2016

17. Murad GJA, Clayman M, Seagle MB, White S, Perkins LA, Pincus DW: Endoscopic-assisted repair of craniosynostosis. Neurosurg Focus 19(6):E6, 2005

18. Rehder R, Abd-El-Barr M, Hooten K, Weinstock P, Madsen JR, Cohen AR: The role of simulation in neurosurgery. Childs Nerv Syst 32:43-54, 2016

19. Shah MN, Kane AA, Petersen JD, Woo AS, Naidoo SD, Smyth MD: Endoscopically assisted versus open repair of sagittal craniosynostosis: the St. Louis Children's Hospital experience. J Neurosurg Pediatr 8:165-170, 2011

20. Tubbs RS, Loukas M, Shoja MM, Wellons JC, Cohen-Gadol AA: Feasibility of ventricular expansion postmortem: a novel laboratory model for neurosurgical training that simulates 
intraventricular endoscopic surgery. J Neurosurg 111:11651167,2009

21. Zymberg S, Vaz-Guimarães Filho F, Lyra M: Neuroendoscopic training: presentation of a new real simulator. Minim Invasive Neurosurg 53:44-46, 2010

\section{Disclosures}

Aesculap, Inc. loaned the endoscopy equipment free of charge for the model assessment. Medtronic, Inc. loaned the drills used in the simulations free of charge for the model assessment. Lumitex, Inc. loaned the lighted retractors used in the simulations free of charge for the model assessment.

\section{Author Contributions}

Conception and design: Eastwood, Bodani, Looi, Drake. Acqui- sition of data: Eastwood. Analysis and interpretation of data: Eastwood, Bodani, Haji, Drake. Drafting the article: Eastwood. Critically revising the article: all authors. Reviewed submitted version of manuscript: Eastwood, Haji, Naguib, Drake. Approved the final version of the manuscript on behalf of all authors: Eastwood. Statistical analysis: Eastwood. Administrative/technical/ material support: Bodani, Haji, Looi, Naguib. Study supervision: Naguib, Drake.

\section{Supplemental Information}

Previous Presentations

The content of this manuscript was presented in part as an abstract submission to the 2017 AANS annual meeting, which was held in Los Angeles, CA.

\section{Correspondence}

Kyle W. Eastwood: The Hospital for Sick Children, Toronto, ON, Canada.kyle.eastwood@sickkids.ca. 